\title{
The effect of the magnitude of response-independent food on conditioned enhancement
}

\author{
ROBERT J. HAMM \\ Virginia Commonwealth University, Richmond, Virginia 23284 \\ and \\ DONALD MELTZER \\ Southern Illinois University, Carbondale, Illinois 62901
}

\begin{abstract}
Twelve hooded rats were trained to barpress for sucrose reinforcement on a variable-interval 2-min schedule. After response rates had stabilized, a respondent conditioning procedure was superimposed on the operant response baseline. The procedure involved presenting a 2-min light (CS) and following it with the delivery of response-independent food (US) while subjects barpressed for sucrose reinforcement. One group $(n=6)$ received a high-magnitude US (three food pellets) at the end of the 2 -min light $\mathrm{CS}$. A second group $(\mathrm{n}=6)$ received a low-magnitude US (one food pellet) at the end of the 2-min light CS. Results showed that the low US magnitude produced an increase in barpresses during the CS. The high-magnitude US resulted in no significant change in operant baseline responding during the CS.
\end{abstract}

An area of continuing interest in basic research in learning is the interaction between operant and respondent conditioning procedures. A typical method used to investigate this interaction is to positively reinforce subjects for making some operant response and then superimpose a respondent CS-US contingency on the operant response baseline. Changes in operant responding during the CS are assumed to provide information concerning the interaction of operant and respondent procedures. Most research in this area has used an aversive US. For example, Estes and Skinner (1941) demonstrated that the presentation of a CS positively correlated with an electric shock US produced suppression of operant responding during the CS. The observation of conditioned suppression using an aversive US is well established (e.g., Davis, 1968).

Rescorla and Solomon (1967) have proposed a mechanism through which the respondent conditioning contingency affects the operant response. They suggest that the respondent conditioning contingency establishes a central motivational state that mediates the change in operant responding. According to this position, the CS paired with an aversive US acquires some of the aversive properties of the US, and the aversive motivational state conditioned to the CS mediates a reduction in the appetitively motivated operant behavior. If a CSappetitive US contingency is superimposed on an

The authors wish to thank Fred P. Rosen for his assistance in the analysis of the data. Requests for reprints should be addressed to the first author, Department of Psychology, Virginia Commonwealth University, Richmond, Virginia 23284. appetitively motivated operant baseline, Rescorla and Solomon (1967) predict that operant responding will be enhanced during the CS. However, the change in operant responding during the CS found using an appetitive US is not completely consistent with this prediction. For example, a number of experiments (Bower \& Kaufman, 1963; Estes, 1943; Herrnstein \& Morse, 1957; Morse \& Skinner, 1958) have found that responding is enhanced during the CS that precedes an appetitive US. Other experiments (Azrin \& Hake, 1969; Hake \& Powell, 1970; Kelley, 1973; Van Dyne, 1971), however, have found the opposite result (i.e., responding was suppressed during the CS). Therefore, the results cannot be predicted on the basis of a simple analysis based entirely on the conditioning of a central motivational state.

Experiments by LoLordo, McMillan, and Riley (1974) and Schwartz (1976) suggest that the response topography elicited by the CS, CS location, and CS modality play an important role in mediating a change in operant responding. LoLordo et al. (1974) reinforced different pigeons on a differential reinforcement of low rate schedule for either keypecking or treadle-pressing operant responses. The CS for a grain US was either a change in key illumination or a tone. They found that the keylight CS resulted in suppression of treadle pressing but increased keypecking. The tone CS produced no consistent effects on either operant response. When the CS is located on the response key and is followed by the response-independent US (grain), this is essentially an autoshaping procedure (Brown \& Jenkins, 1968) superimposed on an operant keypecking baseline. Therefore, in this case (i.e., when the operant response is key- 
pecking and the CS is located on the key), the US- and CS-elicited behaviors are identical to the operant response and enhancement of responding is observed. When the CS is not located on the response key (also see Schwartz, 1976), the operant response is suppressed or not changed during CS presentations. Thus, it seems that the compatibility of the CS- and US-elicited behaviors to the operant response topography plays a critical role in the development of conditioned suppression or enhancement.

If the change in operant responding is a result of the elicited behaviors caused by the introduction of the CSUS contingency, then the magnitude of change in operant responding should be a function of US magnitude, since US magnitude has been shown to significantly influence the strength of respondently conditioned behavior (e.g., Passey, 1948). LoLordo (1971) tested the influence of different US magnitudes on the change in operant behavior during the CS. Pigeons were reinforced for keypecking. A keylight CS was paired with different US magnitudes (2-, 4-, 8-sec access to grain). As with LoLordo et al. (1974), the operant response topography was compatible with the behaviors elicited by the particular CS and US employed. Under these conditions, LoLordo observed a direct relationship between US magnitude and the degree of response enhancement recorded during the CS.

If the CS and US do not elicit compatible behavior to the operant response, US magnitude may have a different, and perhaps opposite, effect on operant responding during the CS. The purpose of the present experiment was to investigate the role of US magnitude on operant responding when the CS- and US-elicited behaviors are not compatible with the operant response topography.

\section{METHOD}

\section{Subjects}

The subjects were 12 male hooded rats between the ages of 90 and 120 days at the outset of the experiment. Ten days prior to the start of the experiment, the subjects were placed and maintained on a $23-\mathrm{h}$ food-deprivation schedule. Water was continuously available in the subject's home cage.

\section{Apparatus}

Rats were tested in a standard operant conditioning chamber with interior dimensions of $22.2 \times 19.1 \mathrm{~cm}$. The front wall of the chamber had the following configuration: a response lever $3.2 \mathrm{~cm}$ to the right of the center and $6.4 \mathrm{~cm}$ above the grid floor, an opening for access to a liquid dipper $4.4 \mathrm{~cm}$ from the left wall and $2.0 \mathrm{~cm}$ above the floor, a food-pellet cup located $3.0 \mathrm{~cm}$ from the right wall and $3.0 \mathrm{~cm}$ above the floor, and a light located $14.0 \mathrm{~cm}$ above the liquid dipper opening. The intensity of the light was $7.9 \mathrm{fL}$, measured at a distance of $10 \mathrm{~cm}$. The ambient noise level was $72 \mathrm{~dB}$.

The chamber was placed in a ventilated sound-attenuating ice chest. White noise was always present in the experimental room to mask extraneous noises. Electromechanical relay equipment was located in an adjacent control room and controlled stimulus events and response recording.

\section{Procedure}

Preliminary training phase. During preliminary training the response lever was retracted, and subjects were given five $30-\mathrm{min}$ sessions of dipper training. The dipper contained $.5 \mathrm{cc}$ of $10 \%$ (by weight) sucrose solution and was available to the subjects for $6 \mathrm{sec}$ on a variable-time (VT) 1-min schedule. Following dipper training, four 30-min sessions of food-cup training were conducted. One 45-mg food pellet was delivered into the food cup on a VT 1 -min schedule. Finally, one $30-\mathrm{min}$ session was given in which dipper and food-hopper operations were randomly alternated on a VT 1-min schedule.

Operant conditioning phase. The response lever was now introduced and remained in the chamber for the rest of the experiment. Subjects were conditioned to leverpress for sucrose reinforcement. During the first two 50-min sessions, each leverpress was reinforced with $6-\mathrm{sec}$ access to the $.5-\mathrm{cc} 10 \%$ sucrose solution. For an additional two sessions, leverpresses were reinforced on a variable-interval (VI) 45-sec schedule. Finally, for five more sessions, leverpresses were reinforced on a VI 2-min schedule during each 50-min session.

Testing phase. During the last phase of the experiment, a CSUS contingency was superimposed on the operant response baseline. Subjects were divided into two groups of six subjects each, based on response rates on the last four sessions of the operant training phase. For one group, the high US magnitude group, the duration of the light CS was $2 \mathrm{~min}$, and the termination of the CS coincided with the delivery of a three-food-pellet US (highmagnitude US). For the other group, the low-magnitude US group, the 2-min light CS terminated with the delivery of a onefood-pellet US (low-magnitude US).

Subjects in both groups were exposed to six CS-US pairings in each 50-min session while responding on a VI 2-min schedule of sucrose reinforcement. The mean interval between CS presentations was $6.5 \mathrm{~min}$. This procedure of superimposing a CS-US contingency while the subjects barpressed was followed for 24 sessions.

\section{RESULTS}

The data analyzed were the mean response rate during the pre-CS and CS stimulus conditions, calculated in blocks of four sessions. The pre-CS response rate was calculated by summing the responses during the $2 \mathrm{~min}$ preceding each CS presentation and dividing by 48 , the number of minutes in this stimulus condition during each block of four sessions. The CS response rate was calculated by summing the responses occurring during the 2-min CS over the four sessions of each block and dividing by 48 . The response rate data are shown in Figure 1. In Figure 1 the first block of sessions (labeled B) represents the baseline operant response rate prior to the introduction of the CS-US contingency.

The response rate data were analyzed by a 2 (US magnitude) by 2 (stimulus condition) by 6 (blocks of sessions) analysis of variance. Although response rates during the pre-CS and CS conditions were greater in the high US magnitude condition than in the low US magnitude condition, the main effect of US magnitude was not significant. In the low US magnitude condition, the CS response rate was greater than that during the pre-CS condition, while in the high US magnitude condition, the difference between the CS and pre-CS response rates was in the opposite direction and of a smaller magnitude. This produced a significant interaction of US Magnitude by Stimulus Condition $[\mathrm{F}(1,10)=5.31$, $p<.05]$. No other $F$ tests in the analysis of variance were significant. 


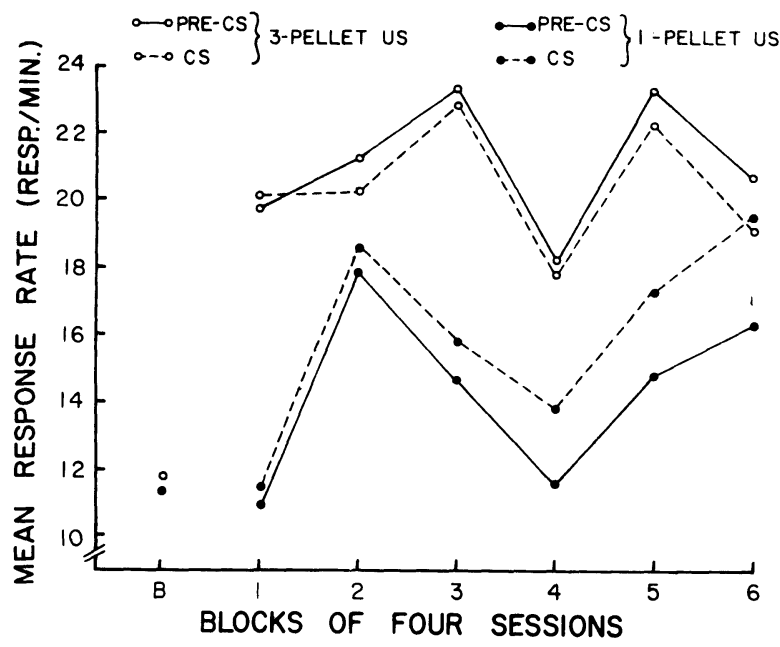

Figure 1. Mean response rates during the pre-CS and CS periods over blocks of sessions for the two US magnitudes. Point $B$ on the abscissa represents the baseline response rate prior to the induction of the CS-US contingency.

Although the analysis of variance indicated that the response rate during the CS and pre-CS conditions depended on the magnitude of the US, this is not a sufficient test for conditioned enhancement or suppression for the US magnitudes. Evidence for conditioned suppression or enhancement is obtained by directly comparing the pre-CS and CS response rates for subjects within each group. If the CS response rate is greater than the pre-CS response rate, it would be evidence for conditioned enhancement. If the pre-CS rate is greater than the CS response rate, it would be evidence for conditioned suppression. In the low US magnitude group on Session Blocks 4-6, the CS response rate was significantly greater than the pre-CS response rate $(\mathrm{t}=2.31$, $2.61,2.12$, respectively, $\mathrm{df}=5, \mathrm{p}<.05$ ). On these blocks of sessions, at least five of the six subjects within the group had a CS response rate greater than that of the pre-CS. In the high US magnitude condition, the pre-CS and CS response rates did not differ significantly over any blocks of testing.

From inspection of Figure 1, it is apparent that the introduction of the CS-US contingency had an abrupt effect on response rate in the three-pellet US condition. A t test on the change in response rate between the block of sessions prior to the introduction of the US (Point B) and the pre-CS response rate on the first block of sessions with the CS-US contingency was significant $[t(5)=2.48, p<.05]$. In the low US magnitude group, the introduction of the CS-US contingency did not significantly increase baseline response rate over any of the six blocks of testing.

\section{DISCUSSION}

Results showed that the CS correlated with the low US magnitude produced reliable enhancement of barpressing, while the
CS correlated with the high US magnitude produced no significant change in responding during the CS. Thus, under the conditions used in this experiment, there was an inverse relationship between US magnitude and the change in operant responding during the CS. This relationship is the opposite of what LoLordo (1971) reported. Using pigeons, a keylight CS, and a keypecking response, LoLordo observed a direct relationship between US magnitude and the change in operant responding. In order to interpret the different effects of US magnitude found by LoLordo and in the present experiment, it is again necessary to examine the relationship between the operant response topography and the behaviors elicited by the CS and US. If the behavior elicited by the US and CS is compatible with the operant response (e.g., keylight CS and keypecking response used by LoLordo), increases in US magnitude will produce an increase in enhancement. This direct relationship between US magnitude and degree of enhancement was confirmed by LoLordo (1971). However, if the CS- and US-elicited behaviors are not identical to the operant response, the magnitude of the US has a different effect. If the US is sufficiently large in magnitude, it may condition responses that are incompatible with the operant response. For example, if the operant response is incompatible with consuming the US (e.g., treadle pressing or barpressing), the subject may stop responding in order to prepare for the delivery of the US, and there will be an inverse relationship between US magnitude and the change in operant responding during the CS.

An analysis of operant-respondent interactions based entirely on the conditioning of competing responses to the operant response yields two predictions about the effect of US magnitude. First, all US magnitudes should result in response suppression during the CS. Second, there should be an inverse relationship between US magnitude and the change operant response rate during the CS. The present experiment supports the second prediction but not the first. One possible reason for the lack of suppression observed in the present experiment is that by stopping the operant response to prepare for US delivery the subject will also reduce the number of response-contingent reinforcements obtained during the CS. This suggests that the subject will reduce responding during the CS only if the US is of a sufficient magnitude to outweigh the possible loss of operant reinforcements. However, as mentioned before, an analysis based entirely on competing responses conditioned to the CS is not satisfactory, since it predicts less response suppression with a low US magnitude rather than the response enhancement that was observed.

A comparison of the present experiment with that of LoLordo et al. (1974) may be helpful in identifying some of the processes that control the mediation of operant responding during the CS. In the present experiment the operant response was barpressing and the CS was a light which illuminated the entire chamber and was located high on the front wall. The closest parallel to the present experiment in the LoLordo et al. (1974) experiment was when the operant response was treadle pressing and the CS was either displayed on the key or was a tone. In neither of these conditions was enhancement of responding found. The present experiment found enhancement only when a low US magnitude was used. When a high US magnitude was employed, there was no significant change in responding during the CS. An analysis of the US in LoLordo et al. (1974) may help explain the lack of a consistent effect observed with the treadle-pressing response. The US in LoLordo et al. was 10 -sec access to grain. This access duration may be considered a high US magnitude, especially when contrasted with the 4-sec access to grain used as the operant reinforcer. Thus, the lack of enhancement that LoLordo et al. obtained with the treadle-pressing response is similar to the results obtained with a high US magnitude with rats barpressing and is compatible with the effect of US magnitude found in the present experiment. 
Some experịments (e.g., Meltzer \& Brahlek, 1970) which have reported enhancement of responding have been criticized because the introduction of the CS-US contingency reduced the operant baseline response rate. Thus, when reporting enhancement of responding during the $\mathrm{CS}$, the enhancement is relative to a decreased response baseline and is not enhancement of responding relative to the response rate prior to the introduction of the US. The enhancement reported in the present experiment is not subject to such a criticism since the baseline response rate did not decrease with the introduction of the US. In fact, the increase in response rate in the high. US magnitude condition with the introduction of the CS-US contingency is similar to the effect found when presenting noncontingent shocks to a subject responding on a shock avoidance schedule (e.g., Rescorla, 1966).

The observation of enhancement in the present experiment poses a special problem for explanations of enhancement that are based solely on the CS- and USeliciting behaviors that are identical to the operant response. In the present experiment it is difficult to imagine a relationship between the response topographies elicited by a food US and a light CS which would increase barpressing during the CS. It is more reasonable to assume that the CS and US elicit behaviors that are incompatible with the operant response. In other words, the evidence of conditioned enhancement of barpressing found by this experiment suggests that the observation of conditioned enhancement is not limited to cases where the CS-US contingency elicits responses that are compatible with or identical to the operant response topography.

\section{REFERENCES}

Azrin, N. H., \& Hake, D. F. Positive conditioned suppression: Conditioned suppression using positive reinforcers as the unconditioned stimuli. Journal of the Experimental Analysis of Behavior, 1969, 12, 167-173.

Bower, G., \& Kaufman, R. Transfer across drives of the discriminative effect of a Pavlovian conditioned stimulus. Journal of the Experimental Analysis of Behavior, 1963, 6, 445-448.

Brown, P. L., \& Jenkins, H. M. Autoshaping of the pigeons key-peck. Journal of the Experimental Analysis of Behavior, 1968, 11, 1-8.

DAvis, H. Conditioned suppression: A survey of the literature. Psychonomic Monograph Supplements, 1968, 2, 283-291(Whole No. 30).

Estes, W. K. Discriminative conditioning: I. A discriminative property of conditioned anticipators. Journal of Experimental Psychology, 1943, 32, 150-155.
Estes, W. K., \& Skinner, B. F. Some quantitative properties of anxiety. Journal of Experimental Psychology, 1941, 30, 390-400.

Hake, D. F., \& Powell, J. Positive reinforcement and suppression from the same occurrence of the unconditioned stimulus in a positive conditioned suppression procedure. Journal of the Experimental Analysis of Behavior, 1970, 14, 247-257.

Herrnstein, R. J., \& Morse, W. H. Some effects of response-independent positive reinforcement on maintained operant behavior. Journal of Comparative and Physiological Psychology, 1957, 50, 461-467.

Kelley, D. D. Long-term pre-reward suppression in monkeys unaccompanied by cardiovascular conditioning. Journal of the Experimental Analysis of Behavior, 1973, 20, 93-104.

LoLoRDo, V. M. Facilitation of food-reinforced responding by a signal for response-independent food. Journal of the Experimental Analysis of Behavior, 1971, 15, 49-56.

LoLordo, V. M., McMillan, J. C., \& Riley, A. L. The effects upon food reinforced pecking and treadle-pressing of auditory and visual signals for response-independent food. Learning and Motivation, 1974, 5, 24-41.

Meltzer, D., \& BrahleK, J. A. Conditioned suppression and conditioned enhancement with the same positive UCS: An effect of CS duration. Journal of the Experimental Analysis of Behavior, 1970, 13, 67-74.

Morse, W. E., \& Skinner, B. F. Some factors involved in the stimulus control of operant behavior. Journal of the Experimental Analysis of Behavior, 1958, 1, 103-107.

PAssey, G. E. The influence of intensity of unconditioned stimulus upon acquisition of a conditioned response. Journal of Experimental Psychology, 1948, 38, 420-428.

Rescorla, R. A. Predictability and number of pairings in Pavlovian fear conditioning. Psychonomic Science, 1966, 4, 383-400.

Rescorla, R. A., \& Solomon, R. L. Two-process learning theory: Relationships between Pavlovian conditioning and instrumental learning. Psychological Review, 1967, 74, 151-182.

Schwartz, B. Positive and negative conditioned suppression in the pigeons: Effects of the locus and modality of the CS. Learning and Motivation, 1976, 7, 86-100.

VAN Dyne, G. C. Conditioned suppression with a positive US in the rat. Journal of Comparative and Physiological Psychology, 1971, 77, 131-135.

(Received for publication June 22, 1977.) 